(199)

\title{
Habitat Preferences and Distribution Modelling of the Endangered Frog Pseudophilautus zorro
}

\author{
Rupasinghe U.A.L.D.*, Ukuwela K.D.B., Vandercone R.P.G. \\ Department of Biological Sciences, Rajarata University of Sri Lanka, \\ *deshan1st@gmail.com
}

\begin{abstract}
Amphibians are the most threatened group of vertebrates in the world. In Sri Lanka, $67 \%$ of the amphibians are threatened with extinction largely due to anthropogenic activities. Fundamental to the conservation of amphibians is an understanding of habitat preferences and fine scale distribution of species. Pseudophilautus zorro is an endangered, endemic frog species restricted to Kandy district, Sri Lanka. Thus, a study was initiated to assess the (a) habitat preferences (type of vegetation, leaf litter thickness (LLT), percentage of canopy cover (PCC)), (b) model the fundamental ecological niche to unravel potential areas of occupancy using Ecological niche modeling (ENM) and then to (c) estimate the extent of occurrence (EOO) and area of occupancy (AOO) of $P$. zorro with new locality data and predicted data. Fieldwork was conducted in Gannoruwa Forest Reserve, Udawattakele Forest Reserve and Hanthana Conservation Area from December 2016 to August 2017. Habitat preferences were determined by randomly placing quadrats in different habitats and assessing the number of individuals in each quadrat. Occurrence localities of $P$. zorro from published records and localities from this study were used for ENM in Maxent. At $\alpha=0.05$ level, the results indicate that there is a positive relationship $(\mathrm{r}=0.427, \mathrm{p} \leq 0.013)$ between LLT and number of individuals of $P$. zorro in quadrats. However, there was no significant relationship ( $\mathrm{r}=0.078$, $\mathrm{p} \geq 0.666$ ) between PCC and number of individuals of $P$. zorroin quadrats and no significant variation $(\mathrm{p} \geq 0.404)$ in the occurrences of $P$. zorro among the three habitat types (forest, mahogany and pine plantations) suggesting that vegetation type is not a major determinant of $P$. zorro distribution. ENM predicted highly suitable areas (suitability $>75 \%$ ) in the central province in the Kandy and Matale districts. The EOO and AOO of $P$. zorro with new occurrence data was $22 \mathrm{~km}^{2}$ and $4 \mathrm{~km}^{2}$ respectively, and with predicted data, $1,229.34 \mathrm{~km}^{2}$ and $117 \mathrm{~km}^{2}$, indicating an increase in EOO and AOO. However, the increase in EOO and AOO should be interpreted with caution as the presence of $P$. zorro is yet to be physically confirmed in the predicted areas. The data on habitat preferences and predicted habitats will be useful in formulating in-situ and ex-situ conservation measures, and serves as a useful starting point for future studies on niche modeling of endangered amphibians and similar taxa in Sri Lanka.
\end{abstract}

Keywords: Maxent, Fundamental ecological niche, Leaf litter thickness, Extent of occurrence, Area of occupancy 